\title{
Aplicação do curativo a vácuo em feridas de difícil cicatrização
}

\author{
Gilson de Bitencourt Vieira, M.Sc.*, Cristina Feix Leichtweis**, Ariane de Oliveira Johner***
}

"Enfermeiro da comissão de infecção hospitalar do Hospital Universitário - HU/UFSC, ${ }^{* *}$ Enfermeira, Especialista em Estética e Imagem Corporal pelo Instituto Fisiomar, ***Enfermeira, Graduada pela Universidade Federal de Santa Catarina - UFSC

\begin{abstract}
Resumo
Este estudo abordou a utilização de curativos a vácuo em feridas de difícil cicatrização de diferentes características. Objetivou-se avaliar a eficácia dessa técnica através de imagens fotográficas obtidas antes e após cada troca, observando a evolução das lesões. Foram realizados três estudos de casos e, após utilização do vácuo, comprovaram-se os benefícios a curto e médio prazo. O uso da técnica determinou a redução do exsudato e dos esfacelos, bem como o aumento considerável no tecido de granulação das lesóes, o que resultou um menor tempo de hospitalização para os pacientes e a redução dos custos de internação. Acrescido a isto, evidenciou-se que os profissionais da enfermagem, ao integrarem-se à equipe médica, podem contribuir de forma positiva na assistência ao paciente com feridas complexas, auxiliando na melhoria da sua qualidade de vida.
\end{abstract}

Palavras-chave: Enfermagem, cicatrização, estudos de casos, hospitalização.

\section{Abstract \\ Application of vacuum dressings on wounds difficult to heal}

This study approaches the use of dressings under negative pressure in hard healing wounds and wounds with different characteristics. The objective was to evaluate this new technique through photos taken before and after each dressing exchange, observing the healing evolution. The three analyzed cases had proven the benefits of the use of this type of dressing, which, on a short term, caused the reduction of exudates and slough and also a considerable increase in lesion granulation tissues, resulting in internment costs reduction and hospitalization time reduction. Added to that, was observed that nursing professionals, integrated in the medical team, can contribute in a good way on the assistance for patients with complex wounds, improving their quality of life.

Key-words: Nursing, wound healing, case studies, hospitalization.

Artigo recebido em 7 de janeiro de 2011; aceito em 3 de fevereiro de 2012. Endereço para correspondência: Gilson de Bitencourt Vieira, Rua Brigadeiro Silva Paes, 811 I/11 204, 88101-250 Campinas São José SC, Tel: (48) 3721-9862, E-mail: vieira862@hotmail.com, cleichtweis@hotmail.com, ariane_johner@yahoo.com.br 


\section{Resumen}

\section{Aplicación de cierre asistido con vacío en las heridas de difícil cicatrización}

Este estudio abordó la utilización de la técnica del cierre asistido con vacío en heridas de difícil cicatrización y de diferentes características. El objetivo fue evaluar la eficacia de esa nueva técnica por medio de imágenes fotográficas obtenidas antes y después de cada cambio de vendaje, observándose la evolución de las lesiones. Se realizó un estudio de tres casos y, después de la utilización de la técnica mencionada, se ha demostrado los beneficios a corto y mediano plazo. El uso de esta técnica llevó a la reducción de exsudado y los esfacelos, así como el considerable aumento del tejido de granulación, resultando en menor cantidad de días de hospitalización de los pacientes y en la reducción de los costos de dicha hospitalización. Se observó que los profesionales de enfermería, mediante la integración con el equipo médico, pueden contribuir positivamente en la asistencia del paciente con heridas complejas, aportando a la mejoría de su calidad de vida.

Palabras-clave: Enfermería, cicatrización de heridas, estudios de casos, hospitalización.

\section{Introdução}

O tratamento de ferimentos de diversas etiologias é fonte de preocupação para o ser humano desde o início dos tempos, pois além de causarem dores e sangramentos propiciam à entrada de microorganismos prejudiciais à saúde, podendo levar a consequências fatais.

Nesta perspectiva, as feridas são compreendidas como rupturas na continuidade de qualquer estrutura anatômica, devido a traumas, processos inflamatórios, degenerativos, circulatórios, distúrbios metabólicos ou defeitos de formação [1]. Quando ocorre um dano tecidual, inicia-se o processo de cicatrização, que envolve uma sequência de fenômenos bioquímicos e fisiológicos interagindo para restabelecer a integridade dos tecidos [2].

A preocupação em viabilizar meios que promovam a cura de feridas remete a milhares de anos. $\mathrm{Na}$ era pré-histórica, já eram tratadas com cataplasmas de ervas que serviam para controlar hemorragias e promover a cicatrizaçáo [2]. Com o passar do tempo, foram utilizadas substâncias como mel, excrementos de animais, álcool, cinzas e óleos, como aceleradores no processo da cura [1].

No período medieval, algumas pessoas com conhecimento de química, herbologia e rituais diversos, alcunhadas muitas vezes de bruxas, tratavam as feridas através de magias e plantas medicinais $[2,3]$.

No final do século XIX e início do século $\mathrm{XX}$, surgiram os antissépticos, tais como: líquido de Dakin, derivados de iodo e mercúrio, além de alguns agentes tópicos com ação antimicrobiana, bem como a preocupação em proteger as feridas com coberturas secas.
Ainda no século XX, a enfermeira Florence Nightingale percebeu que a limpeza de ambientes com água pura, drenagem eficiente de secreções e iluminaçáo adequada poderiam ajudar na cura de doenças e feridas infectadas; métodos que desde então fazem parte dos cuidados nos serviços de saúde.

Atualmente, os curativos são realizados com materiais estéreis e os cuidados com feridas permeiam o conceito ideal de assepsia [4,5], com a utilização de líquidos antissépticos e o material aplicado diretamente sobre uma ferida, o qual tem como objetivo facilitar a cicatrizaçáo e prevenir complicaçóes das lesóes contaminadas, bem como, absorver secreçôes e proteger fisicamente as feridas, além de promover o conforto ao paciente $[6,7]$.

Autores descrevem o processo de cicatrização em três fases: inflamatória, proliferativa e fase de maturação [8].

A fase inflamatória, também denominada de exsudativa, reativa ou defensiva, ocorre no exato momento da lesão, atraindo no primeiro momento os neutrófilos e monócitos com objetivo de desbridar as superfícies da ferida e fagocitar as partículas antigênicas e corpos estranhos $[6,8]$.

A fase proliferativa, conhecida como regeneração, reconstrutiva ou fibroblástica, tem como características a formação do tecido de granulação, neo-angiogênese, com síntese de colágeno responsável pela força e sustentação da cicatriz. As células endoteliais migram das bordas da ferida para o leito, diminuindo sua extensão. Esta fase se estende por aproximadamente três a quatro semanas [8].

Já a maturação consiste na fase final do processo; é a mais longa e se inicia na $3^{\text {a }}$ semana. Caracteriza-se pelo aumento da resistência, apenas 
remodelando o colágeno sem aumentar a sua produção. Com isso aumenta a força da cicatriz e diminui seu tamanho [8].

É importante salientar que, de acordo com a quantidade de tecido lesado e da presença ou náo de infecção, existem três formas de cicatrização: por primeira, segunda ou terceira intenção. A primeira é caracterizada com perda mínima de tecido, ausência de infecção e edema, e as bordas estáo aproximadas. $\mathrm{Na}$ segunda, há uma perda acentuada de tecido, com presença ou não de infecção e não é possível a aproximação dos bordos cicatriciais, havendo uma produção extensa do tecido de granulação. Já na cicatrização por terceira intenção ocorre a presença de infecção, necessitando de um fechamento secundário ou uma aproximação mecânica dos bordos da ferida $[2,8]$.

O processo de cicatrização pode ser prejudicado, dependendo das características da ferida, do tratamento realizado ou de acordo com a idade e condiçóes clínicas ou a partir do estado imunológico do paciente. No leito da lesão, a oxigenação, perfusão dos tecidos, a utilização de medicamentos também são fatores prejudiciais à cura da ferida. Por isso, torna-se necessário que o enfermeiro tenha conhecimento na avaliação destas lesóes, para, assim, optar por um tratamento mais adequado, realizando uma classificação de acordo com o agente causal, o grau de contaminação e o comprometimento tecidual, o que constituem importantes mecanismos para uma conduta adequada no tratamento de feridas [1]. Sendo assim, no que tange ao tratamento de feridas, percebe-se um avanço tecnológico nas áreas de fisiopatologia e imunologia que atualmente realizam estudos que contribuem para o surgimento de novas técnicas de curativos [1].

Em 1997, durante o Congresso Americano de Curativos, foi apresentado outro conceito de curativo o Vacuum - Assisted Closure (VAC), utilizado pela primeira vez por Usopof e Epifanov na antiga União Soviética, em 1987, o qual pode ser definido como a aplicação de pressão negativa sobre a lesão, proporcionando a retirada do excesso de líquidos da ferida, o aumento da vascularização, a redução da colonização bacteriana com elevação da mitose celular e a produçáo dos fatores de crescimento $[11,12]$. Esta técnica pode ser utilizada em feridas na fase aguda, subaguda e/ou crônicas, limitando-se apenas às feridas que apresentam restos necróticos, tumores, osteomielite náo tratada e fístulas comunicadas com órgáos e cavidades [11].
Contudo, as vantagens desse método são significativas podendo ser relatada a redução do tempo da hospitalização e o baixo custo da técnica. Para que a técnica empregada seja eficiente, é empregada uma pressão negativa sobre a lesão, que pode ser contínua ou intermitente, promovendo uma aproximação das bordas para o centro, sendo considerada ideal uma pressão de $125 \mathrm{mmHg}$ [13-15].

Nas instituiçóes de saúde, cuidar de feridas é um processo fundamental para os profissionais de enfermagem, uma vez que eles permanecem em contato contínuo com os pacientes, acompanhando a evolução das lesóes, adquirindo maior destreza na realização desse procedimento, bem como experimentando um aperfeiçoamento do método.

No que se refere ao novo conceito de curativos sob pressão negativa, é evidente a necessidade de maior exploração e utilização desta técnica por enfermeiros, propiciando uma maior integração à equipe médica, contribuindo, desta maneira, para a realizaçáo de um trabalho eficaz nos cuidados prestados aos clientes.

Este estudo procurou demonstrar a eficácia dessa técnica de curativo, apresentando resultados significativos a curto e médio prazo, por meio de imagens fotográficas registradas, antes, durante e após o tratamento, oferecendo subsídios para aplicação desse curativo em lesóes de diversas causas.

Diante do que foi abordado nesta pesquisa, comprova-se a relevância do tratamento do curativo a vácuo em feridas. Embora na literatura brasileira não tenham sido publicados muitos trabalhos acerca deste tema na área da saúde, acredita-se que este é um novo assunto, que pode ser investigado por profissionais da enfermagem.

\section{Material e métodos}

$\mathrm{O}$ artigo apresenta estudo de caso, como modalidade de pesquisa, que é caracterizado como um instrumento de investigaçáo, que pode ser aplicado em diversas áreas de conhecimento. Visa à investigação de um caso específico, bem delimitado, contextualizado em tempo e lugar para que se possa realizar uma busca circunstanciada de informaçóes [16].

Apresenta como vantagem estimular novas descobertas, enfatizar a multiplicidade de dimensôes de um problema, permitindo uma análise da profundidade dos processos e das relaçóes entre eles e apresentar simplicidade nos procedimentos [16]. Este procedimento é adequado, quando um 
fenômeno é extenso e o corpo de conhecimentos existente é pequeno para permitir a proposição de questóes causais [17].

Assim, para o delineamento da pesquisa, optou-se pelo estudo de caso por analisar situaçóes do contexto atual, desenvolver certos procedimentos, aumentar a compreensão de um fenômeno e ampliar experiência.

Neste estudo foi observada a evolução de três lesóes com curativo sob pressão negativa, entre março a novembro de 2009. Inicialmente foram convidados a fazer parte do estudo três clientes internados em uma unidade de internação cirúrgica de um hospital do sul do Brasil, que seriam submetidos à técnica do curativo por pressão negativa, sendo o único critério de inclusão na pesquisa. Após aceitarem participar do estudo, os pacientes assinaram o Termo de Consentimento Livre e Esclarecido previamente informados sobre os propósitos do trabalho e do compromisso e respeito aos direitos do ser humano, conforme a resoluçáo 196/96 do CONEP/MS. O projeto da pesquisa foi submetido e aprovado pelo Comitê de Ética em Pesquisa com Seres Humanos da Universidade Federal de Santa Catarina, cujo parecer se encontra protocolado sob o registro 370/2008.

Para a aplicação desta nova técnica, foi necessária a utilização de uma espuma de poliuretano esterilizada sobre a ferida, a qual foi coberta por uma película plástica estéril (filme transparente) ligada a um frasco coletor acoplado à rede de vácuo por um intermediário de silicone sob pressáo negativa (Figura 1).

As feridas foram mantidas em uma aspiração contínua através da rede de vácuo que nesta unidade hospitalar oscila entre -10 a $-80 \mathrm{cmHg}$, e para esta técnica de curativo oscilou entre em -40 e -60 cmHg.

Os casos foram acompanhados em períodos diferentes, o que possibilitou um acompanhamento mais efetivo. Os pesquisadores participaram das trocas dos curativos, e registraram as características das lesóes através de imagens fotográficas, antes e após cada troca, inclusive após o término da aplicação do curativo a vácuo.

Em seguida, foi elaborado um arquivo eletrônico para cada participante, com seu histórico pessoal e a descrição das características da evoluçáo das feridas. $\mathrm{O}$ armazenamento desses dados ficou restrito aos pesquisadores, preservando a identidade e dados pessoais dos participantes da pesquisa.

Após a organizaçáo dos resultados, foi realizada a comparação, à medida que a ferida foi evoluindo, considerando sua profundidade, volume e características das secreçóes, bem como, o aumento do tecido favorável de granulação; e finalmente, foram avaliados resultados, comparando com a literatura disponível sobre o tema.

Figura 1 - Curativo a vácuo instalado em uma ferida do membro inferior esquerdo.

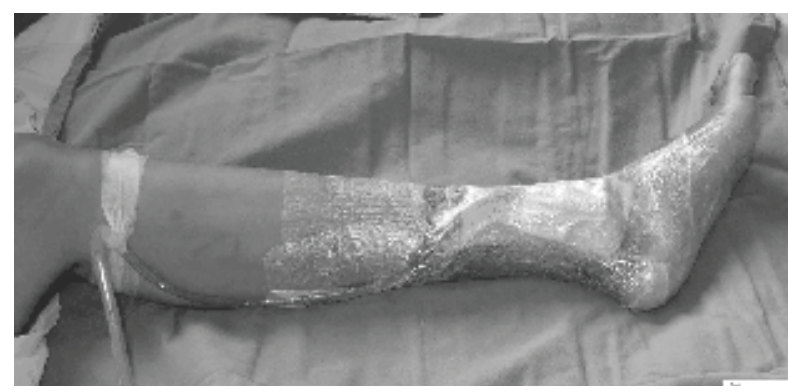

A Figura 1 apresenta um curativo a vácuo instalado, com esponja esterilizada cobrindo a lesáo, sobreposta por uma película (filme) transparente, ligado a uma rede de vácuo por um intermediário de silicone, proporcionando uma pressão negativa na ferida.

\section{Apresentaçáo dos casos}

- Caso I - Paciente do sexo masculino, 23 anos, vítima de múltiplas queimaduras por choque elétrico, resultando na amputação dos pés na altura do metatarso. Inicialmente foram realizados debridamento mecânico e curativos convencionais com aplicação de pasta de hidrocolóide. Após a redução dos esfacelos e tecidos necrosados foi o aplicado curativo a vácuo.

- Caso II - Sexo feminino, 25 anos, apresentando uma ferida na regiáo da panturrilha esquerda agravada por uma anemia falciforme. Nesse caso, foi realizado curativo com papaína a 5\%, porém houve uma redução mínima dos tecidos desvitalizados. Entâo, optou-se na aplicação do vácuo.

- Caso III - Sexo masculino, 32 anos, com uma lesão extensa e profunda na regiáo do tendão de Aquiles, causado por mordedura de cão. Nesse último caso, foram realizados três debridamentos cirúrgicos e curativos convencionais, utilizando cobertura com pasta de hidrocolóide e ácidos graxos essenciais (AGE). Mas, devido à profundidade da lesão, o referido paciente não apresentou melhora significativa. Deste modo, foi aplicado 
o curativo a vácuo.

Em todos os casos, foi realizada enxertia cutânea após a aplicação desta técnica de curativo, pois oferecia condiçốes para este procedimento cirúrgico.

Para coleta e avaliação dos resultados, foram captadas imagens fotográfica, utilizando máquina digital, modelo cyber-shot, 7.2 mega pixels de resolução. As imagens foram obtidas antes da aplicação do vácuo e a cada troca dos curativos. As características das lesões durante todo processo foram anotadas em arquivo próprio dos pesquisadores, sem comprometer a identidade e a privacidade dos participantes do estudo, conforme acordado no TCLE.

\section{Resultados e discussão}

A seguir será apresentado cada caso, considerando o tempo de aplicação dos curativos e as características das lesôes, antes e após sua aplicação.

O tempo de tratamento dependeu da evoluçáo da lesão, considerando as características do tecido e do exsudato, o tamanho da lesão, a localização e a presença dos sinais de infecção.

\section{Caso I}

Figura 2 - Coto de amputação do pé esquerdo antes da aplicação do curativo a vácuo.

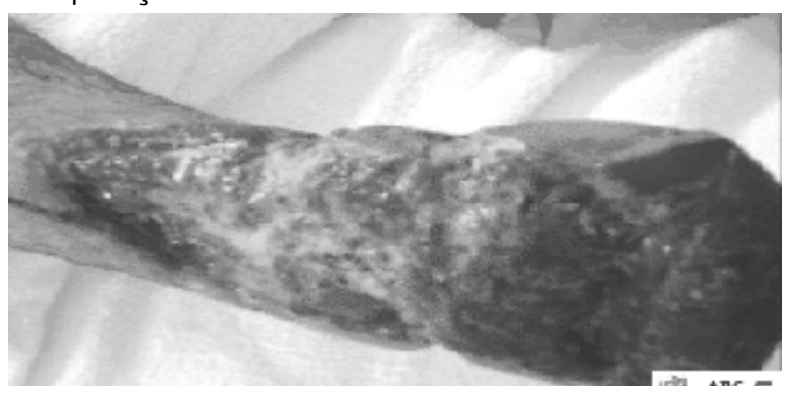

Apresenta tecido favorável de granulação, mas grande parte da lesão está coberta por esfacelos e exsudação purulenta abundante.

$\mathrm{Na}$ Figura 3, observa-se que, após nove dias de aplicação do curativo sob pressão negativa, houve um aumento considerável dos tecidos de granulação, recobrindo os tendóes e o osso anteriormente exposto. Observou-se também a aproximação dos bordos da ferida e uma reduçáo significativa dos esfacelos, bem como exsudação purulenta. Devido a esta recuperação, decorrente da utilização do curativo a vácuo, já foi possível a enxertia cutânea, proporcionando uma completa cicatrização.
Diante do exposto, é notório asseverar que a utilização do curativo a vácuo resulta na elevaçáo da mitose celular, responsável pela produção de fatores de crescimento e aumento da vascularização, promovendo a formação de tecido granulado. $\mathrm{O}$ tecido de granulaçáo vai preenchendo o leito da ferida antes do processo de epitelização. Ele possui uma coloração vermelho-vivo, aparentando ter grânulos e é formado por colágeno, fibronectina e ácido hialurônico, além de ser rico em: macrófagos, fibroblastos e novos vasos sanguíneos [18].

Autores afirmam que o VAC reduz consideravelmente o exsudato purulento do leito das feridas e provoca a diminuição da colonização bacteriana nessa lesão $[11,15]$, pois neste tipo de exsudação há presença de leucócitos e fragmentos celulares, além de bactérias patogênicas, que produzem o pus de coloração branco-amarelada, característica desse tipo de secreção $[11,18]$.

\section{Caso II}

Figura 3 - Ferida no membro inferior esquerdo antes da aplicação do curativo a vácuo.

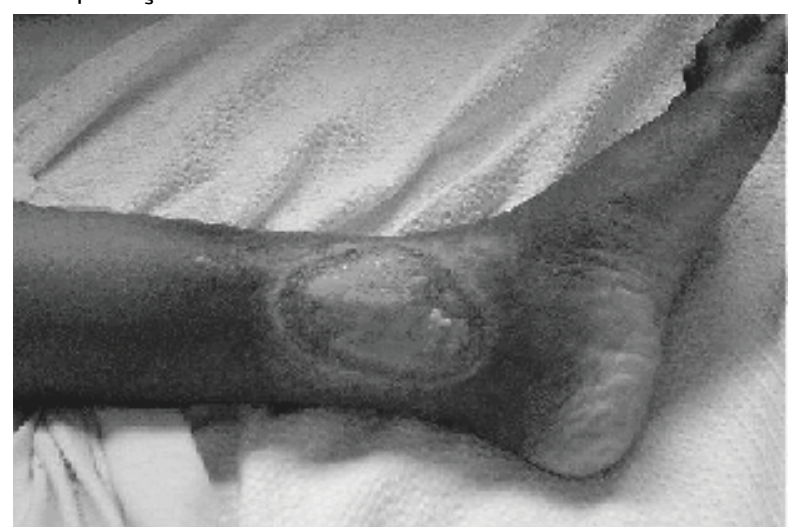

Ferida rasa, com aproximadamente $15 \mathrm{~cm}$ de diâmetro, extremidades pálidas, com aparência desvitalizada, coberta por esfacelos e apenas com uma pequena área de tecido granulado.

Figura 5 - Ferida no membro inferior esquerdo após a aplicação do curativo a vácuo.

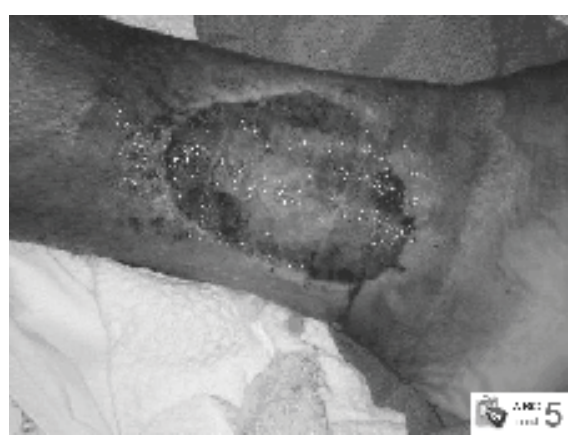


É possível observar na figura 5 que em apenas 72 horas de aplicação do curativo a vácuo, esta lesão apresentou uma melhora considerável, reduzindo praticamente todo o esfacelo no leito da lesão, promovendo a proliferaçáo do tecido favorável de granulação. Notoriamente, apresenta-se mais brilhante e menos pálida.

Nesta lesão havia, inicialmente, grande quantidade de esfacelos com posterior redução significativa. A área de esfacelos surge quando ocorre isquemia no leito da ferida e se inicia o processo de desvitalização, resultando na morte celular e alterando a coloração do tecido para amarelada. Os esfacelos podem preceder à formação de tecido necrótico $[18,19]$. O curativo sob pressão negativa favorece a vascularizaçáo da ferida, reduzindo gradativamente a área com fibrina [11].

O emprego do vácuo cria uma pressão subatmosférica que induz um "novo trauma", determinando o estímulo à transformação de uma ferida de fase crônica em uma ferida de fase aguda com migração de células de defesa e estímulo à neoangiogênese [20]. Além disso, consegue-se um ambiente limpo ao redor da lesão, demandando a necessidade de menos trocas e, desta forma, reduzindo o risco de contaminação da ferida [21].

\section{Caso III}

Figura 6 - Ferida no membro inferior direito antes da aplicação do curativo a vácuo.

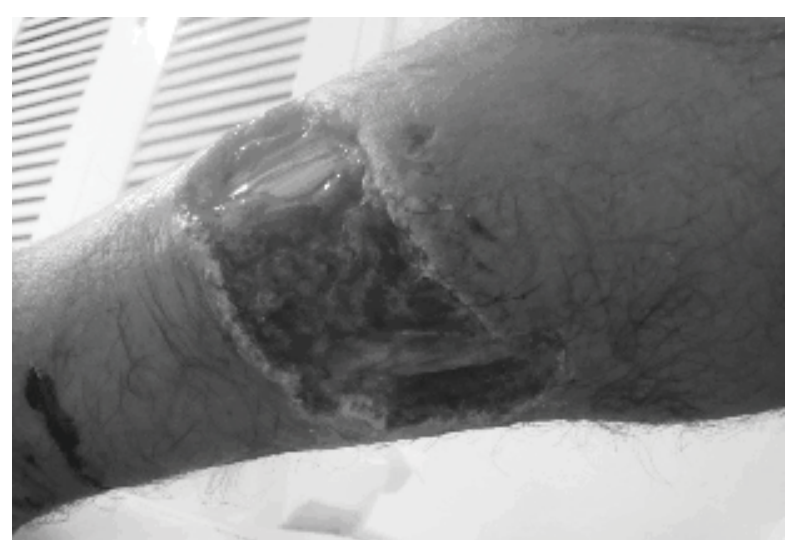

Essa figura revela, antes da aplicação do curativo a vácuo, uma lesão extensa e profunda, com bordos macerados, exposição extensa dos tendóes e de estrutura óssea, com pequena quantidade de esfacelos, altamente exsudativa.
Figura 7 - Ferida no membro inferior direito após a aplicação do curativo a vácuo.

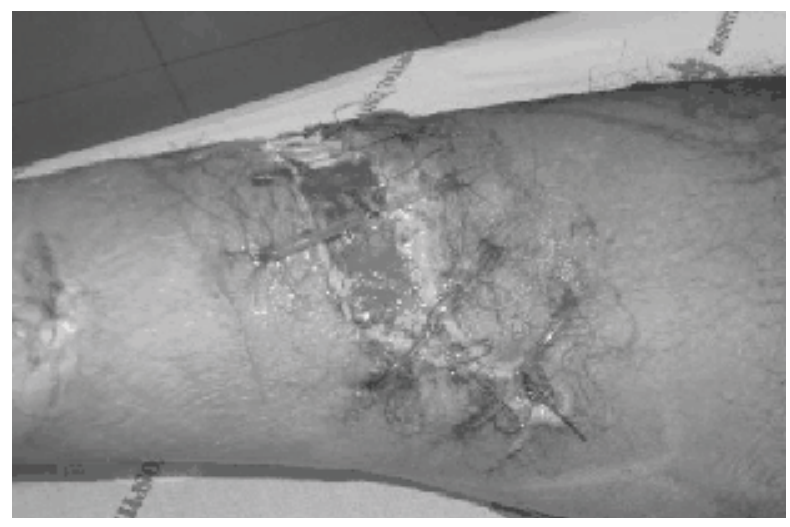

Observa-se que, após seis dias de utilização de curativo por pressáo negativa com troca a cada 48 horas, houve um aumento do tecido de granulação, cobrindo a exposição óssea e dos tendóes. Como a ferida era extensa, houve a necessidade de uma aproximaçáo dos bordos com pontos de reforço até oferecer condiçóes para receber enxerto cutâneo.

Um estudo realizado na Universidade Federal de Pernambuco (UFPE) reforça a eficácia da aplicação desta nova técnica, por ter apresentado resultados excelentes no tratamento de feridas abertas com infecçóes graves, ferimentos extensos com danos aos tecidos e exposiçáo de estruturas nobres, devido ao desenvolvimento de tecido de granulação, melhora da circulação local, possibilitando, assim, a execução de novo processo, ou seja, fechamento por segunda intenção, fechamento primário, enxertia ou cutânea [12].

Em síntese, na presente pesquisa todos os pacientes obtiveram melhora significativa das lesóes após o emprego do curativo a vácuo, sendo possível realizar a enxertia cutânea. Ressalta-se através deste estudo que, mesmo em feridas crônicas e/ou infectadas, esta técnica oferece excelentes resultados. Os materiais utilizados para a confecção do curativo são de baixo custo e de fácil acesso na rede hospitalar. Destaca-se ainda a rapidez e a eficácia do tratamento, que refletem consideravelmente na redução do período da permanência hospitalar, o que geralmente não ocorre com a utilização de outras coberturas de curativo. 
A busca por inovaçóes no tratamento de feridas tem evoluído com o tempo, sendo prioridade para os enfermeiros envolvidos com a melhoria da qualidade de vida dos pacientes. Estes profissionais têm demonstrado interesse em aprimorar novas técnicas, utilizando vários tipos de coberturas disponíveis no mercado para acelerar a cicatrização de feridas.

O curativo por pressão negativa se mostrou eficaz neste estudo, pois, com pequeno período de utilização, proporcionou melhora significativa em lesôes de diversas etiologias que apresentavam difícil processo de cicatrização. Como consequência disto, tem-se um menor tempo de hospitalização, fator que protege o paciente de uma exposiçáo prolongada ao ambiente hospitalar, no qual está susceptível a novas infecçóes, além de reduzir os custos da hospitalização.

É importante salientar que apesar de o curativo sob pressão negativa limitar o paciente ao leito, já que fica em repouso relativo, ele nos assegura um menor tempo de hospitalização deste, devido à rápida recuperação da lesão.

Os três casos estudados revelaram os benefícios do uso do curativo a vácuo, amplamente utilizado em outros países principalmente nos Estados Unidos, porém ainda pouco conhecido no Brasil. Assim, ressalta-se a importância de socializar os resultados através de imagens fotográficas para confirmar os efeitos positivos dessa técnica, sendo que a mesma apresentou efeitos positivos mesmo nas lesôes de maior complexidade. Os resultados obtidos neste estudo servem para elucidar que com essa técnica, o tecido de granulação e o fechamento da lesão são mais rápidos do que se tem observado em outras terapias convencionais.

Diante do exposto, percebe-se que a equipe de enfermagem tem grande importância no cuidado com os pacientes em uso do curativo a vácuo, porque estão prestando constantemente assistência, podendo acompanhar diariamente as condiçóes do curativo e discutir com a equipe as condutas a serem seguidas. Os profissionais de enfermagem deverão atuar como sujeitos ativos neste processo e não como meros observadores, objetivando a melhoria da qualidade de vida do ser humano a qual assistem.
1. Borges EL. Evolução da cicatrização. In: Borges EL, Saar SRC, Lima VLAN, Gomes FSLG, Magalhães MBB. Feridas: como tratar. Belo Horizonte: Coopmed; 2001.p.17-29.

2. Jorge AS, Dantas SRPE. Abordagem multiprofissional do tratamento de feridas. São Paulo: Atheneu; 2003.

3. Candido LC. Livro do Feridólogo: tratamento clínico-cirúrgico de feridas cutâneas agudas e crônicas. Santos: Núcleo Interdisciplinar de Pesquisa e Tratamento de Feridas; 2006.

4. Madella O. História do tratamento de ferida [internet]. São Paulo: Podólogo Orlando Madella Júnior. [citado 2009 Mai 15]. Disponível em URL: http://www. podologiabr.com

5. Manhezi AC, Bachioni MM, Pereira AL. Utilização de ácidos graxos essenciais no tratamento de feridas. Rev Bras Enferm 2008;61(5):620-9.

6. Martins GH, Oliveira AC. Feridas e curativos. In: Amaral CFS, Pedroso ERP, Fonseca JGM, Rocha MOC, Couto RC, Leal SS et al., eds. Enciclopédia da saúde: infecçáo hospitalar. Rio de Janeiro: Medsi; 2001. p.59-69.

7. Irion G. Feridas: novas abordagens, manejo clínico e atlas em cores. Rio de Janeiro: Guanabara Koogan; 2005.

8. Tazima MFGS, Vicente YAMVA, Moriya T. Biologia da ferida e cicatrização. Medicina (Ribeirão Preto) 2008;41(3):259-64.

9. Mandelbaum SH, Santis EP, Mandelbaum MHS. Cicatrização: conceitos atuais e recursos auxiliares - parte I. An bras Dermatol 2003;78(4):393-410.

10. Clark RAF. Cutaneous tissue repair: basic biologic considerations. J Am Acad Dermatol 1985;13:701-25.

11. Jimenez CEJ. Terapia de presión negativa: una nueva modalidad terapéutica en el manejo de heridas complejas, experiencia clínica con 87 casos y revisión de la literatura. Rev Colomb Cir 2007;22(4):209-24.

12. Ferraz EM Lira CH, Martins JP, Maricevich JP, Pradines SM, Granja Filho LG. Uso do sistema VAC no tratamento da fascite necrosante da parede abdominal. Rev Col Bras Cir 2007;34(4):264-71.

13. Glenn I. Feridas: novas abordagens, manejo clínico e Atlas em cores. 1st ed. Guanabara Koogan: Rio de Janeiro; 2005.

14. Poletti NAA, Caliri MHL, Simáo CSR, Juliani KB, Tácito VE. Feridas malignas: uma revisão de literatura. Rev Bras Cancerol 2002;48(3):411-17.

15. Ferreira MC, Wada A, Tuma Jr P. The vacuum assisted closure of complex wounds: report of 3 cases. Rev Hosp Clin 2003;58(4):227-30.

16. Ventura MM. O estudo de caso como modalidade de pesquisa. Rev SOCERJ 2007;20(5):383-86.

17. Alyrio RD. Metodologia Científica. Rio de Janeiro: PPGEN/Universidade Federal do Rio Janeiro; 2008. 
18. Ferreira SRS, Périco LAD. Assistência de enfermagem à pacientes com feridas em serviços de atenção primária à saúde. Mom \& Perspec Saúde 2002;15(1):39-52.

19. Balbino CA, Pereira LM, Curi R. Mecanismos envolvidos na cicatrização: uma revisão. Rev Bras Ciênc Farm USP 2005;41(1):27-51.

20. Braakenburg A, Obdeijn MC, Feitz R, Van Rooij IALM, Van Griethuysen AJ, Klinkenbijl JHG. The clinical efficacy and cost effectiveness of the vacuum-assisted closure technique in the management of acute and chronic wounds: a randomized control trial. Plast Reconstr Surg 2006;118(2):390-6.

21. Gomoll AH, Lin A, Harris MB. Incisional vacuum-assisted closure therapy. J Orthop Trauma 2006;(20):70511. 